
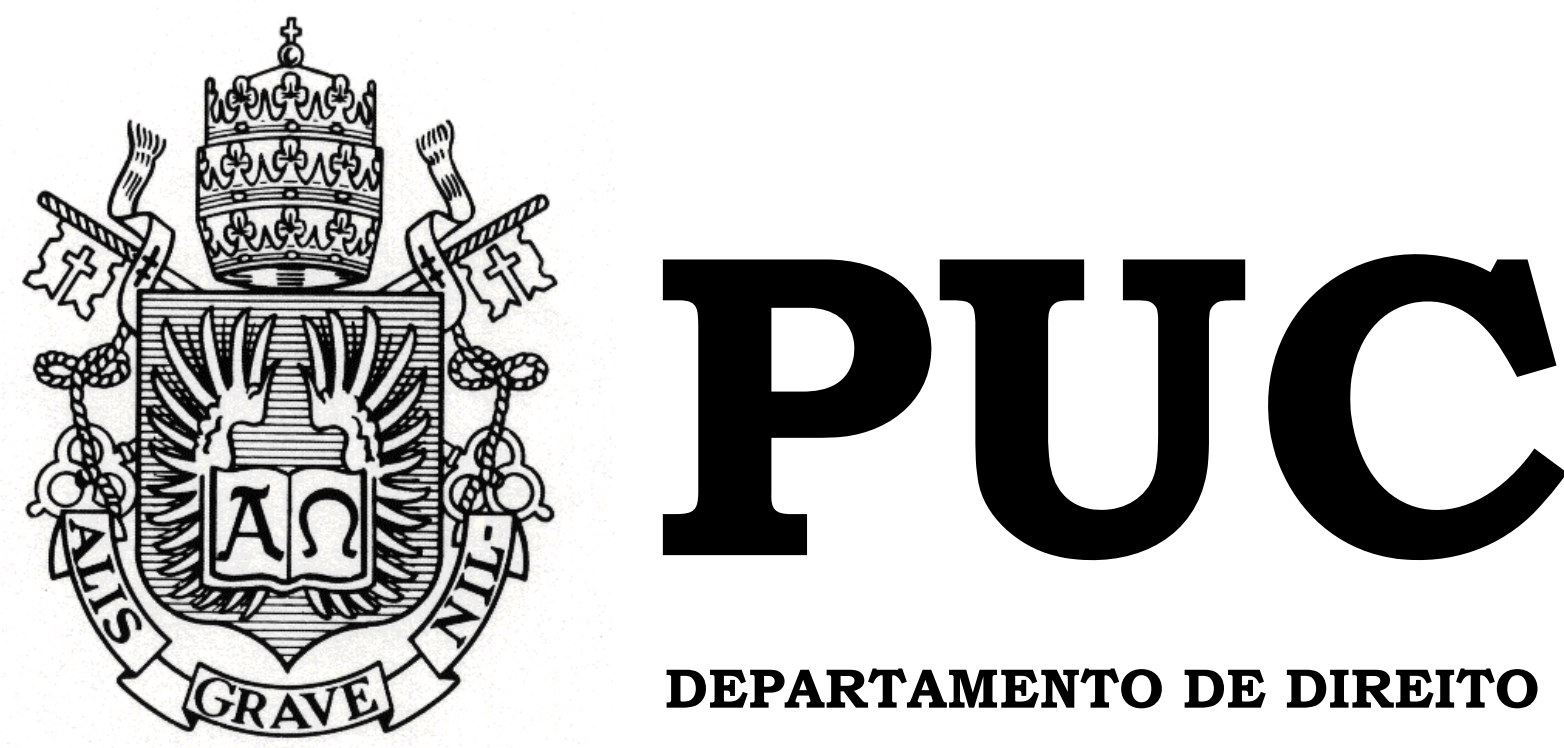

DEPARTAMENTO DE DIREITO

\title{
PLANEJAMENTO SUCESSÓRIO PATRIMONIAL
}

por

Plinio César dos Santos Sales

ORIENTADOR: Álvaro Piquet Pessoa

2009.1

PONTIFÍCIA UNIVERSIDADE CATÓLICA DO RIO DE JANEIRO

RUA MARQUÊS DE SÃO VICENTE, 225 - CEP 22453-900

RIO DE JANEIRO - BRASIL 
PONTIFÍCIA UNIVERSIDADE CATÓLICA DO RIO DE JANEIRO RUA MARQUÊS DE SÃO VICENTE, 225 - CEP 22453-900

RIO DE JANEIRO - BRASIL

\section{PLANEJAMENTO SUCESSÓRIO PATRIMONIAL}

por

Plinio César dos Santos Sales

Monografia apresentada ao Departamento de Direito da Pontificia Universidade Católica do Rio de Janeiro (PUC-Rio) para a obtenção do Título de Bacharel em Direito.

Orientador: Álvaro Piquet Pessoa 
Dedico à minha esposa, pela paciência e companheirismo durante esta jornada acadêmica. 


\section{Agradecimentos}

Aos meus pais pelo sempre presente e fundamental incentivo e apoio. 


\section{Resumo}

SALES, Plínio César dos Santos. Planejamento Sucessório Patrimonial. Rio de Janeiro, 2009. 45p. Monografia de Final de Curso de Graduação Departamento de Direito. Pontifícia Universidade Católica do Rio de Janeiro.

O indivíduo que ao longo de sua vida acumula patrimônio pode assumir uma postura passiva em relação ao destino de seus ativos após sua morte ou pode buscar interferir na forma com que seus bens serão transferidos e distribuídos aos seus herdeiros. As razões para se desejar influenciar a própria sucessão patrimonial são inúmeras. Destinar parte dos bens a herdeiros não previstos na lei, prevenir disputas familiares pela herança, ou até mesmo beneficiar aqueles por quem o autor da herança tenha mais carinho ou, na mais das vezes, maior preocupação.

Para se lograr estes objetivos, no entanto, tem-se a disposição um completo arsenal de instrumentos jurídicos e financeiros. Utilizando-os, em conjunto ou isoladamente, pode-se obter os mais diversos e significativos efeitos no patrimônio, nas relações familiares e afetivas, nos sonhos e na qualidade de vida dos futuros herdeiros.

Um plano sucessório patrimonial eficaz depende de um profundo conhecimento dos desejos, preocupações e preferências do titular do patrimônio. Mas isto é só o início.

\section{Palavras-Chave}

Sucessões; Planejamento Sucessório; Planejamento Patrimonial 
La continuitá della vita nell umanitá traverso la catena non interrotta delle generazioni, che si succedono mediante il rinnovarsi costante degli elementi ond essa si compone, implica necessariamente la continuitá nel godimento dei beni, necessari alla conservazione e allo svillupo progressivo della vita stessa.

(Cimbali, La nuova fase del diritto civile ) 


\section{Sumário}

1. Introdução

2. Direito Sucessório Brasileiro

2.1. Aspectos gerais da sucessão

2.1.1. Lei aplicável à sucessão

2.1.2. Sucessão legítima e testamentária

2.1.3. Ordem da vocação hereditária e os efeitos dos diversos regimes de comunhão

2.1.4. Direitos do companheiro vs. direitos do cônjuge

2.2. Tributação na transferência de ativos

2.2.1. Imposto de transmissão causa mortis e por doação

2.2.2. Imposto de Renda

3. Planejamento Sucessório

3.1. Introdução

3.2. Objetivos do planejamento sucessório

3.2.1. Preservação de bens

3.2.2. Preservação da atividade empresarial familiar

3.2.3. Liberação rápida de recursos e ativos

3.2.4. Prevenção de discussões sucessórias e disputa pela herança

3.2.5. Proteção de herdeiros naturais ou terceiros

3.3. Limites e cautelas ao planejar a sucessão patrimonial

3.3.1. O direito do herdeiro necessário

3.3.2. As alterações na família

4. Instrumentos disponíveis para se planejar a sucessão

4.1. Testamento, doação e usufruto

4.2. Planos de previdência privada

4.3. Seguro de vida 
4.4. Contas conjuntas

4.5. Holdings patrimoniais

4.6. Escolha do regime de bens

4.7. Cláusulas de incomunicabilidade, impenhorabilidade e inalienabilidade

4.8. Trusts

4.9. Fideicomisso

5. A importância da seleção da carteira de ativos

6. Conclusão

Referências Bibliográficas 


\section{INTRODUÇÃO}

Com o falecimento de uma pessoa, seus herdeiros são convocados a suceder em seu patrimônio. Tal chamamento pode ser determinado exclusivamente pela lei, ou influenciado pela vontade do falecido. Ou seja, pode o indivíduo interferir na forma e nas conseqüências da distribuição de seu patrimônio quando de sua morte. E para ver sua vontade respeitada o instrumento primordial e mais difundido é o testamento.

Contudo, este não é o único instrumento que pode auxiliar o indivíduo a planejar a sucessão de seu patrimônio. Existem diversas ferramentas jurídicas e financeiras que podem garantir que se transmita um patrimônio de maneira eficaz e eficiente, atingindo os objetivos desejados, de maneira rápida e a um custo reduzido. Ademais, tampouco se necessita aguardar o falecimento de alguém para se transferir seu patrimônio aos herdeiros desejados. Meios também há que viabilizam a antecipação da implementação de um plano sucessório patrimonial, ainda que se deseje manter a fruição do patrimônio por seu titular até sua morte.

As ferramentas e instrumentos disponíveis para se elaborar e executar um planejamento sucessório patrimonial, assim como os seus objetivos, benefícios e restrições serão tema deste trabalho. Primeiramente, no entanto, se apresentará um panorama geral da regra sucessória patrimonial vigente no Brasil. O intuito é de nivelar o conhecimento do leitor e introduzir os conceitos básicos do direito sucessório brasileiro.

Após cobrir os principais institutos que moldam o cenário de uma sucessão sob a vigência de nossa lei pátria, se introduzirá o conceito de planejamento sucessório patrimonial, abordando seus principais direcionadores, vantagens e limitações. Já com uma visão clara do 
arcabouço legal sucessório patrimonial, e com ciência do potencial de se, antecipadamente, planejar a transmissão de bens aos herdeiros, se apresentarão os principais instrumentos jurídicos e financeiros disponíveis para se executar de forma satisfatória o plano elaborado. Tal apresentação, como urge ser, incluirá não só as principais características de cada ferramenta, mas também as hipóteses mais corriqueiras em que seu uso viabiliza a estrutura sucessória patrimonial desejada.

Fundamental é, desde já, alertar que um adequado planejamento é “personalíssimo”. Ou seja, a arquitetura a ser proposta deve ser pensada de maneira individualizada, atendendo aos objetivos, situação patrimonial, contexto familiar e preferências de cada indivíduo, que, não se faz necessário argumentar, nunca serão idênticos aos de qualquer outra pessoa. Imperativo, ainda, considerar as evoluções por ocorrer na vida e nos desejos do indivíduo que assume a empreitada de planejar o destino de seu patrimônio. Ora, um bom plano deve ter flexibilidade suficiente para acomodar as futuras alterações na situação de vida e patrimonial do titular da herança, caso contrário, corre o risco de caducar rapidamente, ou ainda pior, não surtir os efeitos desejados.

\section{Direito Sucessório Brasileiro}

\subsection{Aspectos gerais da sucessão}

\subsubsection{Lei aplicável à sucessão}

A lei aplicável à sucessão de bens localizados no Brasil, sejam móveis ou imóveis, corpóreos ou incorpóreos, é a lei do último domicílio do de cujus, "aquele de cuja sucessão se trata" ${ }^{1}$ independente de sua

\footnotetext{
${ }^{1}$ MAXIMILIANO, Carlos. Direito das Sucessões. $2^{\text {a }}$ ed.. Rio de Janeiro: Editora Freitas Bastos, 1942. pg 35.
} 
nacionalidade. $^{2}$ Assim, as regras a serem aplicadas na transmissão de patrimônio localizado no Brasil serão as da lei brasileira quando o autor da herança aqui tiver o seu domicílio, seja ele brasileiro ou estrangeiro. Por outro lado, na hipótese de brasileiro domiciliado em outro país deixar para seus herdeiros patrimônio localizado no Brasil, aplica-se a lei sucessória alienígena para se aferir direitos e obrigações.

A exceção a esta regra é trazida pela Constituição Brasileira ${ }^{3}$, que visa proteger cônjuges e filhos brasileiros de estrangeiros. A sucessão dos bens situados no Brasil de um estrangeiro domiciliado em outro país será regulada pela lei brasileira, sempre que esta for mais favorável ao seu cônjuge ou filhos brasileiros.

Com relação à sucessão de bens de brasileiros localizados no exterior, a norma adotada pode variar, "a depender da regra de conexão local aplicável à sucessão. Enquanto o Brasil adota o critério do domicílio, outros países adotam o critério da nacionalidade para a sucessão internacional”. ${ }^{4}$ Assim, há de se verificar a opção do legislador do local de situação dos bens, para se apurar qual lei sucessória é aplicável.

No aspecto temporal, o Código Civil Brasileiro, lei 10.406 de 10 de janeiro de 2002, estipula que a sucessão e a legitimação para suceder serão reguladas pela lei vigente ao tempo do óbito do autor da herança. ${ }^{5}$ Ou seja, as sucessões abertas a partir de 11 de janeiro de 2003, data de início da vigência do atual código, de falecidos domiciliados no Brasil serão reguladas por este, até que novo ordenamento nacional o substitua.

\footnotetext{
${ }^{2}$ ARAUJO, Nadia. Direito Internacional Provado: Teoria e Prática Brasileira. $4{ }^{\mathrm{a}}$ ed. Rio de Janeiro: Editora Renovar, 2008. pg 472. LICC art 10.

${ }^{3}$ CFB art. $5^{\circ}$, XXXI.

${ }^{4}$ ARAUJO, Nadia. Direito Internacional Provado: Teoria e Prática Brasileira. 4 a ed. Rio de Janeiro: Editora Renovar, 2008. pg 470.

${ }^{5}$ CCB 2002, art. 1.787.
} 


\subsubsection{Sucessão legítima e testamentária}

Há duas espécies de sucessão patrimonial previstas em nosso ordenamento: a legítima, resultante da lei, e a testamentária, decorrente de disposição de última vontade. ${ }^{6}$ Se o autor da herança não deixar testamento válido, a transmissão de todo seu patrimônio se dará para as pessoas expressamente indicadas pela lei. Se o fizer, mas não elencar no instrumento a integralidade de seu patrimônio, os bens não mencionados, expressa ou implicitamente, também serão transmitidos aos herdeiros previstos pela lei. Neste caso teremos a combinação de ambas as espécies, o que podemos nomear de sucessão mista.

Na hipótese de haver um testamento válido regulando a transmissão da totalidade do patrimônio, tratar-se-á de uma sucessão testamentária. Observar-se-á, então, “o que o testador houve por bem determinar, atribuindo-se assim a herança às pessoas indicadas pelo disponente no ato de última vontade". 7

“A distinção entre as espécies de sucessão”, observa Guilherme Calmon Nogueira Gama, "não apenas se refere ao título da vocação, mas também se estende aos efeitos, já que na sucessão legítima somente haverá herdeiro, ao passo que na sucessão testamentária pode ser instituído herdeiro e/ ou legatário". "Os herdeiros, não importando o número, recebem uma fração indivisa do patrimônio, até que sua quota parte se materialize na partilha”. 9 O legatário sucede em um ou mais bens determinados, usualmente referidos como legados.

\footnotetext{
${ }^{6}$ CCB, art. 1.786 .

${ }^{7}$ MONTEIRO, Washington de Barros. Curso de Direito Civil: Direito das Sucessões. $35^{\mathrm{a}}$ ed. São Paulo: Editora Saraiva, 2003. pg 9.

${ }^{8}$ GAMA, Guilherme Calmon Nogueira. Direito Civil: Sucessões. $2^{\mathrm{a}}$ ed. São Paulo: Editora Atlas, 2007. pg. 8.

${ }^{9}$ VENOSA, Sílvio de Salvo. Direito Civil: Direito das Sucessões. $9^{\mathrm{a}}$ ed. São Paulo: Editora Atlas, 2009. pg. 10.
} 
Importante, no entanto, mencionar, que a liberdade de estipulação do testador em nosso ordenamento não é absoluta. Deve ele, se tiver herdeiros necessários, isto é, descendentes, ascendentes ou cônjuge ${ }^{10}$, preservar a metade de seus bens, em valor, para estes. ${ }^{11}$ "É o que se denomina legítima dos herdeiros necessários”12, prevista no artigo 1.846 do Código Civil.

\subsubsection{Ordem da vocação hereditária e os efeitos dos diversos regimes de comunhão}

De acordo com o disposto no artigo 1.829 do Código Civil, a sucessão legítima se dá na seguinte ordem:

“I - aos descendentes, em concorrência com o cônjuge sobrevivente, salvo se casado este com o falecido no regime da comunhão universal, ou no da separação obrigatória de bens; ou se, no regime da comunhão parcial, o autor da herança não houver deixado bens particulares;

II - aos ascendentes, em concorrência com o cônjuge;

III - ao cônjuge sobrevivente;

IV - aos colaterais.”

Os incisos acima são excludentes, ou seja, somente se chamará para suceder os ascendentes na hipótese de não haver descendentes. Ou, ainda, somente participarão da transmissão de bens os colaterais (até $4^{0}$ grau: irmãos, primos, etc) na hipótese do falecido não ter deixado descendentes, ascendentes ou cônjuge vivos. Aplica-se, portanto, o princípio da preferência de classes, que, contudo, acabou prejudicado no Código Novo pela inclusão potencial do cônjuge na primeira classe em concorrência com os descendentes.

\footnotetext{
${ }^{10} \mathrm{CCB}$, art. 1.845 .

${ }^{11}$ CCB, art. 1.789.

${ }^{12}$ VENOSA, Sílvio de Salvo. Direito Civil: Direito das Sucessões. $9^{\mathrm{a}}$ ed. São Paulo: Editora Atlas, 2009. pg. 113.
} 
Convoca-se, então, os descendentes em primeiro lugar, concorrendo, todavia, com o cônjuge sobrevivente, exceto nos regimes de casamento e hipóteses descritas acima. Dentre eles, pelo princípio da preferência de graus plenamente em vigor, os em graus mais próximo excluem os mais remotos. Ou seja, os netos somente serão chamados a suceder por direito próprio, quando já não haja nenhum filho vivo.

Poderão, no entanto, ser chamados a participar da sucessão por direito de representação, o que, por certo, não afeta o princípio da preferência de graus. Na hipótese do de cujus ter tido mais de um filho, e um deles já ter morrido ao tempo da sucessão, os filhos deste, netos daquele, o representarão, tendo, em conjunto, o mesmo direito à parcela patrimonial de seu avô, que seus tios herdarem. Se, no entanto, todos os filhos do de cujus já tiverem falecido ao tempo da abertura da sucessão, e conseqüentemente restarem para sucessão apenas os netos, a divisão patrimonial se dará por cabeça, ou seja, cada neto, por direito próprio, receberá cota equivalente do patrimônio inventariado.

\subsubsection{Direitos do companheiro vs. direitos do cônjuge}

A Constituição de 1988 alçou a união estável do homem e da mulher a entidade familiar a ser protegida. "Contudo", afirma o mestre Sílvio de Salvo Venosa, “em que pesem algumas posições doutrinárias e jurisprudenciais isoladas, tal proteção não atribuiu direito sucessório à companheira ou companheiro.” Apenas através de duas leis da década de 90, Lei 8.971/94 e Lei 9.278/96, que modificaram substancialmente o "patamar de direitos relativos à convivência"13, passou-se a reconhecer "em favor dos companheiros certos direitos sucessórios."14 O principal deles foi

\footnotetext{
${ }^{13}$ Ibid. pg 137.

${ }^{14}$ PEREIRA, Caio Mário da Silva. Instituições de Direito Civil: Direito das Sucessões. 16 a ed. Rio de Janeiro: Editora Forense, 2007. pg 162.
} 
a inserção do companheiro na ordem de vocação hereditária, em condição de herdeiro único na falta de descendentes e ascendentes. ${ }^{15}$

O Código Civil de 2002 deveria ter, de uma vez por todas, sistematizado a sucessão do companheiro, equiparando-a à do cônjuge. No entanto, nas palavras de Sílvio Venosa, o Novo Código "conseguiu ser perfeitamente inadequado ao tratar do direito sucessório dos companheiros”. ${ }^{16}$ Críticas não faltam ao novo texto. Elas vão desde contestar a localização física das novas regras na lei, ou seja, em que capítulo foram inseridas, até uma reprovação total das discrepâncias criadas em relação aos direitos do cônjuge. Fato é que não há, sob nenhum aspecto, uma sistematização das regras sucessórias deste e do companheiro. Pior, o novo Código cria diferenças nos direitos de ambos que são em realidade inexplicáveis e injustificáveis diante da realidade atual da família brasileira.

O companheiro, assim como o cônjuge, concorre com os descendentes na sucessão do outro. Contudo, diversas discrepâncias podem ser apontadas entre as duas situações. Em primeiro lugar, enquanto para o cônjuge o regime de casamento é matéria relevante para se determinar a concorrência, para o companheiro não o é. Ou seja, independente do regime de bens adotado pelos companheiros, na morte de um, o outro sempre concorrerá com os descendentes.

Em segundo lugar, há diferença substancial na estipulação dos bens ao que os indivíduos casados e os com união estável estabelecida têm direito de herdar. Os companheiros possuem direitos sucessórios apenas em relação aos bens adquiridos onerosamente na vigência da união estável, Os casados, no regime de bens de comunhão parcial, apenas para destacar a opção legal padrão e a mais difundida atualmente, não só não possuem

\footnotetext{
${ }^{15}$ Lei 8.971/94 art. $2^{0}$, III.

${ }^{16}$ VENOSA, Sílvio de Salvo. Direito Civil: Direito das Sucessões. $9^{\mathrm{a}}$ ed. São Paulo: Editora Atlas, 2009. pg. 144.
} 
direitos sucessórios sobre os bens acima mencionados, como também herdam uma parcela dos bens particulares do cônjuge, que no caso da relação de união estável são integralmente destinados aos descendentes.

Uma terceira diferença inexplicável do novo código é a diferenciação, inexistente para os casados, do valor da quota a ser recebida pelo companheiro sobrevivente quando concorrer com descendentes comuns ao casal ou com filhos e netos só do autor da herança. Na primeira hipótese, terá direito a percentual do patrimônio equivalente ao que por lei for atribuída a cada filho, ou a cada neto, se nenhum filho vivo houver na data da abertura da sucessão. Na segunda hipótese, “tocar-lhe-á a metade do que couber” ${ }^{\prime 17}$ ao descendente que herdar por direito próprio. Por último, é importante notar a proteção adicional que possui o cônjuge na hipótese do casal ter um grande número de descendentes comuns. Assegura o Novo Código Civil ao viúvo uma quota mínima hereditária de 25\% (vinte e cinco por cento) se estiver concorrendo apenas com descendentes de que seja ascendente $^{18}$, previsão esta inexistente no caso de uma união estável. ${ }^{19}$

Ao concorrer com os ascendentes, os companheiros também possuem direitos que não espelham exatamente os dos cônjuges. A estes tocará um terço da herança se concorrer com sogro e sogra, metade em qualquer outro caso. ${ }^{20}$ Ou seja, se houver um só ascendente de primeiro grau, ou qualquer outro número de ascendentes de grau superior. Ao companheiro, por sua vez, sempre caberá um terço da herança quando concorrer com um ou mais ascendentes do falecido, não importando o grau de parentesco. ${ }^{21}$ -

\footnotetext{
${ }^{17}$ CCB art. 1.790, II.

${ }^{18}$ CCB art. 1.832.

${ }^{19} \mathrm{CCB}$, art. 1.832 .

${ }^{20}$ CCB art. 1.837.

${ }^{21}$ CCB art. 1.790, III.
} 
Na situação onde não haja ascendentes ou descendentes vivos do de cujus se cria, talvez, a maior discrepância de regras. Nesta hipótese, o companheiro não é necessariamente herdeiro único como ocorre com o cônjuge. Se houver algum outro parente sucessível, como por exemplo, irmãos ou primos, ele concorrerá com estes, tendo direito a apenas um terço da herança. ${ }^{22}$

Por último, convém mencionar que o Novo Código Civil não elencou o companheiro no rol dos herdeiros necessários, assim como o fez com o cônjuge. Assim, pode o indivíduo convivendo em união estável ser totalmente excluído da sucessão de seu companheiro por ato de última vontade deste. Para Guilherme Calmon Nogueira da Gama, "a inclusão do cônjuge na condição de herdeiro necessário representa o prestígio legal às autênticas e efetivas uniões fundadas no casamento, servindo como estímulo às pessoas para que convertam suas uniões informais”. ${ }^{23}$

\subsection{Tributação na transferência de ativos}

\subsubsection{Imposto Sobre Transmissão Causa mortis e Doação}

Sobre o patrimônio transmitido por doação ou por morte incide o imposto sobre Transmissão Causa Mortis e Doação, tributo de competência dos estados. ${ }^{24}$ Sua alíquota varia de estado para estado, atualmente atingindo o percentual máximo de oito por cento, de acordo com estipulação do Senado Federal. ${ }^{25}$ Importante notar que tal tributação tem como fato gerador a transmissão de propriedade de qualquer bem ou direito, ou seja incide da mesma forma sobre uma doação em dinheiro, como sobre o legado de um imóvel. A arrecadação compete ao estado da situação do

\footnotetext{
${ }^{22}$ CCB art. 1.790, III.

${ }^{23}$ GAMA, Guilherme Calmon Nogueira. Direito Civil: Sucessões. $2^{\mathrm{a}}$ ed. São Paulo: Editora Atlas, 2007. pg. 132.

${ }^{24}$ CFB art. 155, I.
} 
imóvel, ou quando bem móvel, ao estado em que se processar o inventário ou tiver domicílio o doador. ${ }^{26}$

No Estado do Rio de Janeiro a alíquota é de 4\% (quatro por cento), e o contribuinte é o adquirente do bem ou direito. ${ }^{27}$ "A base de cálculo do imposto é o valor real dos bens ou direitos, ou o valor do título ou crédito, transmitidos ou doados. Entende-se por valor real o valor corrente de mercado do bem ou direito" ${ }^{28}$ Nas hipóteses de doação da nua-propriedade ou instituição de usufruto a base de cálculo é de cinqüenta por cento do valor do bem. ${ }^{29}$

\subsubsection{Imposto de Renda}

Em princípio, não há incidência de imposto de renda sobre bens recebidos por doação, legado ou herança. No entanto, uma situação deve ser analisada para melhor compreensão dos impactos na apuração de imposto de renda do donatário, legatário ou herdeiro. Os bens transmitidos, se de valor expressivo, como, por exemplo, imóveis, deverão estar, por certo, informados na declaração de ajuste anual do doador, ou do de cujus. A transmissão poderá ocorrer pelo valor do bem declarado nesta. Ou seja, ainda que tal valor esteja defasado da realidade de preços do mercado, pode-se utilizá-lo para registrar o bem na declaração de imposto de renda do donatário, legatário ou herdeiro. Tal procedimento, não dará ensejo ao pagamento de imposto de renda.

Contudo, neste caso, ficará o donatário, legatário ou herdeiro com o encargo de recolher imposto de renda sobre todo ganho de capital

\footnotetext{
${ }^{25}$ CFB art. 155, parágrafo 10, IV.

${ }^{26}$ CFB art. 155, parágrafo $1^{\circ}$, I e II.

${ }^{27}$ Lei Estadual $\mathrm{n}^{\circ} 1.427$ / 1989, arts. 5 e 17.

${ }^{28}$ Lei Estadual $n^{0} 1.427$ / 1989, art. 10.

${ }^{29}$ Lei Estadual n ${ }^{0} 1.427$ / 1989, art. 11, I.
} 
decorrente de uma futura alienação do bem por preço de mercado superior ao valor registrado em sua declaração de ajuste. É por obvio que tal apuração de ganho de capital poderá ser isenta de imposto de renda, se algumas das previsões legais de isenção se aplicarem ao caso concreto, como, por exemplo, a alienação do único imóvel do indivíduo que não ultrapasse o valor de $\mathrm{R} \$ 440.000,00$ (quatrocentos e quarenta mil reais), quando não tenha havido nenhuma outra alienação nos últimos cinco anos. $^{30}$

\section{Planejamento Sucessório Patrimonial}

\subsection{Introdução}

O indivíduo que ao longo de sua vida acumula patrimônio pode assumir uma postura passiva em relação ao destino deste após sua morte, ou pode buscar, utilizando os instrumentos legais e financeiros disponíveis, interferir na forma com que seus bens serão transferidos e distribuídos aos seus herdeiros, sejam eles determinados pela lei, ou por sua própria vontade. As razões para se desejar influenciar a própria sucessão patrimonial são inúmeras. Pode-se almejar desde destinar parte dos bens a herdeiro não previsto no rol dos legítimos, até prevenir disputas familiares pela herança, ou mesmo beneficiar, dentre os herdeiros necessários aquele por quem o autor da herança tem mais carinho ou, na mais das vezes, maior preocupação.

Abaixo estão listados os principais objetivos a se alcançar na elaboração de um plano sucessório. Dentro de cada tópico se buscará exemplificar as hipóteses mais comuns de sua ocorrência. Importante notar que raramente se encontrará situação real em que apenas um destes

\footnotetext{
${ }^{30}$ Lei 9250 /1995, art. 23.
} 
objetivos estará presente. O cenário mais freqüente e realístico é aquele que reúne diferentes necessidades e desejos, o que torna a tarefa de criar um plano sucessório patrimonial verdadeiramente desafiadora e única.

Não se poderia, no entanto, terminar este capítulo sem abordar as limitações existentes ao se planejar a transferência de bens de um indivíduo aos seus herdeiros e legatários. Algumas se colocam por determinação legal, sendo a necessidade de se preservar a legítima o seu epítome. Outras se fazem presentes por razões fáticas, como, por exemplo, alterações na composição da família entre o momento da elaboração do plano sucessório e o do efetivo falecimento do autor da herança. Tais limitações, conseqüentemente, implicam a adoção de algumas cautelas por parte do arquiteto sucessório. Cautelas estas também debatidas ao final desta seção.

\subsection{Objetivos do planejamento sucessório}

\subsubsection{Destinação racional e preservação de bens}

A herança é um conjunto de bens indivisível que se transmite aos herdeiros por ocasião da abertura da sucessão. Em regra, quando não se trata de sucessão testamentária, cada herdeiro legítimo convocado a suceder tem direito a uma quota parte deste monte indivisível. Caso não seja possível um acordo entre eles, a probabilidade maior que a partilha se dê de forma que cada herdeiro receba, em cada bem transmitido, sua quota parte. Por exemplo, se o monte a ser partilhado for composto de dois imóveis de valores similares, e existam dois herdeiros com direitos sucessórios idênticos, dois irmãos, cada um receberá a metade de cada imóvel.

Nesta hipótese, ter-se-á formado um condomínio na propriedade de cada imóvel. Tal situação, se não causaria transtorno na maioria dos casos, seria altamente indesejada quando se tratassem de irmãos que tivessem 
relacionamento belicoso. Tampouco seria racional e eficiente tal desfecho, caso um dos imóveis se tratasse de uma fazenda em localização remota e o outro um apartamento cravado em bairro movimentado de uma metrópole, quando um dos irmãos preferisse a vida no campo e o outro fosse um adorador da vida urbana.

Tal ingênuo e simplista exemplo ilustra o potencial de se racionalizar a distribuição dos bens, de forma a evitar indesejadas e, muitas vezes, destrutivas discussões entre herdeiros, e a simplificar o processo de alocação de bens aos herdeiros de acordo com suas afinidades.

Pensemos, agora, em um cenário onde parte dos bens a se transferir seja uma coleção de arte, amealhada ao longo de toda uma vida. Pode o autor da herança ter o desejo de manter tal acervo reunido após sua morte. Seria, portanto, desejável destinar este conjunto de bens, naturalmente divisível, a um único legatário, que teria a incumbência de preservá-lo.

\subsubsection{Preservação da atividade empresarial familiar}

Parcela relevante do patrimônio de qualquer empreendedor se materializa nas quotas ou ações que possui das sociedades empresárias nas quais participa. No momento de sua morte, se nenhum planejamento antecipado for realizado, tais quotas ou ações, com o conseqüente poder de gestão sobre as sociedades, serão transmitidas, na maioria dos casos, ao cônjuge, companheiro ou filhos. Ocorre que em alguns casos tais familiares não possuem afinidade com a atividade empresarial do empreendedor, ou não possuem qualquer vocação para gestão empresarial. Assim, de uma hora para outra, a sociedade empresária se vê sendo gerida, ou pelo menos co-gerida nos casos de existência de outros sócios controladores, por indivíduos que não receberam a necessária preparação, ou não detêm 
mínima experiência para a empreitada. As consequiências, não se faz necessário ilustrar, podem ser catastróficas.

Nestes casos, planejar a sucessão patrimonial pode aumentar em muito as chances de sobrevivência da atividade empresarial da família. Por exemplo, na hipótese de um dos filhos ter dedicado sua vida profissional à sociedade familiar, tendo acompanhado seu pai ou mãe na gestão dos negócios, poderia ele ser aquinhoado com ações ordinárias, com poder de voto e gestão da sociedade, enquanto seu irmão, que se dedicara à atividade não relacionada ao ambiente empresarial, receberia ações preferenciais, aquelas com direito a receber os dividendos da sociedade empresária, mas sem, contudo, poder influenciar em sua gestão. Com esta solução exemplificativa, se preservaria o direito patrimonial dos dois herdeiros, salvaguardando as melhores chances de sucesso da atividade empresarial familiar.

\subsubsection{Liberação rápida de recursos e ativos}

Um processo de inventário pode levar anos até que se conclua, especialmente se os herdeiros não concordarem entre si e fomentarem uma feroz batalha sobre os bens deixados. Tal lapso temporal pode ocasionar diversos inconvenientes, desde tornar difícil a vida dos herdeiros que necessitem dos recursos herdados para se sustentar, até destruir o valor de ativos que se deteriorem com o tempo sem a adequada manutenção.

Pensemos na situação de um filho que não tenha renda própria e que após a morte de seu pai necessite sobreviver com os recursos acumulados por este, em seu próprio nome, em um fundo de investimento ou conta poupança. Caso não seja herdeiro único, ou não esteja de acordo com os outros herdeiros, precisará aguardar o fim de um longo processo judicial 
para ter acesso aos ativos financeiros herdados e que lhe garantirão o sustento.

Ora, instrumentos financeiros há que proporcionam disponibilidade imediata dos recursos acumulados. Os planos de previdência privada são um exemplo. Instrumentos jurídicos também existem que previnem tal situação. A doação, mesmo que como antecipação de legítima, é um deles.

\subsubsection{Prevenção de discussões sucessórias e de disputa pela herança}

Uma família pode viver em grande harmonia por um longo período de tempo, até que chega o momento de repartir o patrimônio acumulado pelo patriarca ou matriarca. Nesta hora é possível que o respeito, a colaboração e a relação afetiva outrora existentes desapareçam. A disputa por bens e dinheiro pode levar à ruína o relacionamento entre familiares. Para que o bom entendimento histórico, pautado no amor e na racionalidade, desapareça, pode bastar um mal entendido, ou um movimento precipitado de um dos herdeiros. A partir do momento que se instale um ambiente beligerante entre os sucessores, o amor é substituído pelo ódio e a racionalidade pelo desejo de tirar o maior proveito da situação ou de magoar e prejudicar o outro.

Para preservar o relacionamento entre os herdeiros e prevenir disputas, pode-se lançar mão de diversas estratégias jurídicas. O testamento, onde o autor da herança tem a oportunidade de manifestar expressamente seus últimos desejos é ferramenta muito eficaz na pacificação familiar. Mas, talvez, sozinho não baste. A antecipação da distribuição dos bens aos filhos com reserva de usufruto, por exemplo, pode também reduzir os riscos de disputas e mal entendidos entre herdeiros. 
Estratégias financeiras também podem contribuir para uma sucessão patrimonial serena e pacífica. A opção de transformar grande parte do patrimônio acumulado em ativos com alta liquidez, como por exemplo cotas de fundos de investimento ou ações de companhias comercializadas em bolsa de valores, pode facilitar em muito a distribuição do patrimônio entre os herdeiros. Ora, aqui, pelo menos, se evitará a discussão de valor dos bens e a formação de condomínios.

\subsubsection{Proteção de herdeiros ou terceiros}

Não é rara a situação onde um indivíduo tenha a preocupação de proporcionar uma proteção especial a um familiar ou a alguém de seu convívio próximo após sua morte. Tal cenário pode se materializar no caso de existência de um filho ou neto portador de necessidades especiais, um pai idoso, ou um cônjuge ou companheiro que não tenha capacidade laboral.

Aqui, novamente, um bem elaborado planejamento sucessório pode prover as proteções e seguranças desejadas. As ações possíveis vão desde, por via testamentária, destinar uma maior parcela do patrimônio, a chamada parte disponível, ao familiar que se queira proteger, até constituir um trust, instrumento jurídico de grande flexibilidade previsto nos países com sistema legal baseado no commom law, que será debatido mais adiante.

\subsection{Limites e cautelas ao planejar a sucessão patrimonial}

\subsubsection{O direito do herdeiro necessário}

O Código Civil Brasileiro determina que pelo menos cinqüenta por cento do patrimônio de qualquer indivíduo deve ser destinado aos seus 
herdeiros necessários. São eles: os descendentes, os ascendentes e o cônjuge. ${ }^{31}$ Assim, tem-se o mais relevante limite à capacidade de se livremente dispor de seu patrimônio, o que sem dúvida impõe substanciais restrições ao que se pode lograr com um plano sucessório.

Importante notar, que tal restrição não se aplica somente às disposições de última vontade inseridas em testamento. Qualquer ato realizado em vida, como, por exemplo, uma doação, que ultrapasse este limite legal não poderá gerar todos os efeitos desejados. Neste caso, o donatário, quando da abertura da sucessão deverá ajustar contas com os herdeiros necessários.

\subsubsection{Alterações na família}

A antecedência é o mote do planejamento sucessório. No entanto, é ela própria que impõe algumas cautelas às soluções que serão construídas para se fazer prevalecer a vontade de quem planeja sua sucessão. As relações familiares estão cada vez mais dinâmicas. Casamentos e uniões estáveis, hoje, se constituem e se desfazem com velocidade talvez nunca antes vista. E como não poderia ser diferente, como fruto destas vivências muitas vezes são gerados filhos, relações familiares e obrigações, que em momento anterior não se poderia prever.

Todas estas possibilidades, novos casamentos, separações, filhos de diferentes uniões, não só complicam o mapa da realidade sucessória, mas também impõe a utilização de ferramentas de planejamento que tenham suficiente flexibilidade para acomodá-las. Imaginemos, apenas como ilustração, que um indivíduo tenha doado em vida todo seu patrimônio aos filhos, reservando-lhe o usufruto dos bens. Tal opção pode ter-lhe atendido

\footnotetext{
${ }^{31}$ CCB arts.1.845 e 1.846
} 
o desejo de evitar discussões sucessórias futuras entre seus herdeiros. Contudo, o que ocorreria se tal pai zeloso, já em fase madura da vida, se engajasse em um novo relacionamento afetivo, e fruto desta união nascesse um outro sucessor seu? Como refazer a divisão patrimonial de forma a acomodar os direitos do filho caçula?

Certamente, neste caso se criaria um problema. Problema este que poderia ter sido evitado se a transferência patrimonial antecipada não tivesse abarcado a integralidade do patrimônio existente, e tivesse sido combinada, por exemplo, com o uso de um testamento. As estipulações deste, como não têm caráter definitivo, poderiam ser alteradas após a concepção do novo filho, de forma a restabelecer o equilíbrio na divisão dos bens.

\subsubsection{Alterações na legislação sucessória ou tributária}

Em 11 de janeiro de 2003 entrou em vigência o Novo Código Civil. Ele trouxe radicais alterações nas regras sucessórias patrimoniais. Os direitos do cônjuge e do companheiro sobreviventes, para listar os principais, sofreram fundamentais modificações. Um pouco mais atrás, testemunhamos a constituição de $1988^{32}$ estabelecer "absoluta igualdade entre todos os filhos, não admitindo mais a retrógrada distinção entre filiação legítima ou ilegítima, segundo os pais fossem casados ou não, e adotiva, que existia no Código Civil de 1916.”"33 Atualmente, “todos são apenas filhos, uns havidos fora do casamento, outros em sua constância, mas com iguais direitos e qualificações.” ${ }^{34}$

\footnotetext{
${ }^{32} \mathrm{CFB}$, art, 227, parágrafo $6^{\circ}$.

${ }^{33}$ GONÇALVES, Carlos Roberto. Direito Civil Brasileiro: Direito de Família. $1^{\text {a }}$ ed. São Paulo: Editora Saraiva, 2005. pg. 272.

${ }^{34}$ Ibid. pg. 273.
} 
Ora, a possibilidade de tais alterações nas regras vigentes não pode ser ignorada pelo arquiteto sucessório, sob pena de os efeitos desejados com o planejamento não se concretizarem. É fato que mudanças com a magnitude das mencionadas acima não ocorrem todos os dias. Contudo, em alguns casos, os planos desenhados hoje somente surtirão efeitos concretos dentro de algumas décadas. E se até lá as estruturas sociais tiverem sofrido significativas evoluções, é possível que a legislação as acompanhe.

\subsubsection{Mutações patrimoniais}

Por último, convém debater o talvez mais volátil aspecto de um plano de transferência patrimonial: a possibilidade de mutações significativas na quantidade de bens e no valor dos ativos que se têm disponíveis. Para ilustrar este ponto, pode-se lançar de mão de uma situação muito corriqueira nas grandes cidades: a valorização ou desvalorização acentuada de imóveis ao longo do tempo. Imagine-se um testamento elaborado por um pai, ou mãe, que destine a cada um de seus dois filhos um apartamento em distintas vizinhanças, ambos, na data da elaboração do instrumento, com valores de mercado similares. Se o falecimento do testador acorrer após o transcorrer de algumas poucas décadas, pode ser que o valor relativo dos imóveis tenha sofrido substancial flutuação. Este cenário, se não imaginado e refletido em uma revisão periódica do plano elaborado, irá, com elevado grau de probabilidade, potencializar um conflito entre os herdeiros e criar disparidades que o autor da herança não gostaria de ver ocorrer.

Outra situação que com facilidade assustadora ocorre, e que se não considerada nos diversos cenários do plano sucessório elaborado pode criar sérias dificuldades para seu sucesso é a perda, ou severa diminuição, da capacidade de gerar renda e de se sustentar do titular do patrimônio. Ora, 
em muitos casos se imagina transmitir antecipadamente aos herdeiros todos os bens já amealhados na forma de ativos ilíquidos, como, por exemplo, imóveis, pois se considera que a renda futura ainda a ser gerada e o eventual consumo dos ativos líquidos acumulados serão suficientes para fazer frente aos custos de vida até a morte. Mas, o que fazer se repentinamente se perde a capacidade de gerar renda, devido a, por exemplo, uma grave doença? Ou como fazer os recursos acumulados "durarem" se a vida se prolongar mais do que o esperado?

Para todas estas questões há formas de se precaver. Pode se considerar de antemão a possibilidade de se "consumir" um do bens ilíquidos para custear a sobrevida, ou pode-se incluir na estratégia elaborada proteções advindas de instrumentos financeiros, como os seguros de vida e invalidez ou a contratação de rendas vitalícias com instituições financeiras.

\section{INSTRUMENTOS DISPONÍVEIS PARA SE PLANEJAR A SUCESSÃO}

\subsection{Testamento}

O testamento é o principal e mais difundido veículo jurídico para quem busca realizar sua vontade após a morte. Através dele pode-se nomear herdeiros ou legatários; instituir rendas ou alimentos, temporários ou vitalícios; determinar a quem se deseja destinar determinados bens, portanto, interferindo na partilha; dispensar descendentes de colacionar doações realizadas em vida; reconhecer filhos, conseqüentemente facilitando a defesa de seus interesses sucessórios; declarar a existência e o termo inicial de união estável, auxiliando na estipulação do patrimônio adquirido onerosamente na vigência desta; excluir colaterais, todos ou apenas alguns, da participação hereditária; restringir a livre disposição da herança pelo herdeiro ou legatário através das cláusulas restritivas impenhorabilidade, incomunicabilidade e inalienabilidade; aumentar o 
quinhão de herdeiro, seja companheiro, cônjuge, ascendente, descendente ou colateral... Em suma, as possibilidades de utilização do testamento são extensas e, acima de tudo, flexíveis, o que confere a este instrumento aplicabilidade nas mais diversas necessidades e arquiteturas sucessórias.

\subsection{Doação e Usufruto}

A doação em vida, em contraponto ao testamento que somente produz efeito após a morte do doador, é o meio por excelência para se antecipar a transmissão patrimonial. Pode o doador, por liberalidade, transferir qualquer bem ou direito seu para outra pessoa, por instrumento particular ou escritura pública ${ }^{35}$, sendo a aceitação do donatário, tácita ou expressa, condição necessária para se concretizar a mudança de titularidade.

A doação pode ser acompanhada de encargos. Prevê o artigo 553 do Código Civil que "o donatário é obrigado a cumprir os encargos da doação, caso forem a benefício do doador, de terceiro, ou do interesse geral." ${ }^{36} \mathrm{Ou}$ seja, o donatário não está obrigado a aceitar a doação, mas se o fizer, se obriga a cumprir o encargo, sob pena de revogação da doação. ${ }^{37}$

Pode o doador, também, instituir restrições a livre disposição posterior dos bens ou direitos doados. Através das cláusulas de inalienabilidade, impenhorabilidade e incomunicabilidade, juntas ou individualizadas, pode-se garantir que estes não deixem o patrimônio do donatário. Os efeitos são os mesmos passiveis de obtenção pela utilização destas cláusulas em estipulação testamentária. Importante notar que a

\footnotetext{
${ }^{35}$ CCB, arts. 538 e 541.

${ }^{36} \mathrm{CCB}$, art. 553.

${ }^{37} \mathrm{CCB}$, art. 555.
} 
cláusula de inalienabilidade, mais ampla em seus efeitos, implica em impenhorabilidade e incomunicabilidade. ${ }^{38}$

Pode, ainda, o doador reter para si alguns direitos. O mais difundido e utilizado é a retenção do usufruto. Com esta medida, pode-se transferir a nua-propriedade antecipadamente, com todos os benefícios já discutidos, garantindo ao doador, contudo, o uso, gozo e fruição vitalícios do bem. Outra útil estipulação é a cláusula de reversão, que determina que os bens doados voltem ao patrimônio do doador, caso este sobreviva ao donatário. ${ }^{39}$

Contudo, existem algumas restrições ao poder de doar em vida. A principal delas é a de não poder, no momento da liberalidade, exceder o que se poderia dispor em testamento. ${ }^{40}$ Visa-se com isso preservar a legítima dos herdeiros necessários. Outra restrição importante tem como objetivo salvaguardar a instituição do casamento e a família: a doação feita por cônjuge adultero ao seu cúmplice é anulável. ${ }^{41}$

Por fim, convém mencionar que "a doação de ascendentes a descendentes, ou de um cônjuge a outro, importa adiantamento do que lhes cabe por herança." 42 Sendo certo que pode o doador, no instrumento de doação ou em seu testamento, dispensar da colação as doações realizadas, bastando determinar que saiam de sua parte disponível, contando que não a excedam. $^{43}$

\footnotetext{
${ }^{38}$ CCB, art. 1.911.

${ }^{39}$ CCB, art. 547.

${ }^{40}$ CCB, art. 549.

${ }^{41}$ CCB, art. 550.

${ }^{42}$ CCB, art. 544.

${ }^{43}$ CCB, arts. 2.005 e 2006.
} 


\subsection{Seguro de Vida}

O seguro de vida não é propriamente um instrumento para se planejar a sucessão patrimonial. Ele se encaixaria mais em um conceito de proteção financeira para a família. Sua mecânica básica prevê o pagamento de um valor periódico, chamado prêmio, mensal ou anual, pelo segurado à seguradora, e, na hipótese de sua morte, esta destina o capital estipulado aos beneficiários apontados.

Por que então incluir este produto financeiro no rol dos instrumentos que podem complementar um plano sucessório? Porque ele possui uma característica única, prevista em nosso Código Civil: o capital estipulado, a ser pago na eventualidade do sinistro, não é considerado herança. ${ }^{44}$ A partir deste ponto, se derivam diversas conseqüências muito úteis na elaboração de uma estrutura patrimonial para a sucessão. Em primeiro lugar, deve-se mencionar a velocidade e simplificação burocrática com a qual o montante é liberado ao beneficiário. Em condições normais, basta a apresentação da certidão de óbito do segurado para a seguradora efetuar o pagamento em dinheiro, no prazo de algumas semanas. Ou seja, não é necessário atravessar o potencialmente demorado e burocrático processo de inventário.

Em segundo lugar, existe a questão tributária. Sobre o valor recebido pelo beneficiário não há a incidência do Imposto Sobre Transmissão Causa Mortis e Doação. Por último, apresentam-se a liberdade de estipulação dos beneficiários no contrato de seguro e a irrelevância do valor recebido pelos que também são herdeiros para o cálculo da legítima. Ou seja, o segurado pode estipular como seu beneficiário um de seus herdeiros necessários, deixando de nomear qualquer outro, e aquele não precisará levar o valor recebido à colação. Ou então, pode indicar um terceiro, sem que, com isso, haja redução na parte disponível de seu patrimônio.

\footnotetext{
${ }^{44}$ CCB, art. 794.
} 
O Código Civil previu também a situação onde nenhum beneficiário seja indicado, ou, por qualquer motivo, não prevaleça a indicação. Nestes casos, "o capital segurado será pago por metade ao cônjuge não separado judicialmente, e o restante aos herdeiros do segurado, obedecida a ordem da vocação hereditária." ${ }^{45}$

\subsection{Planos de previdência privada}

Os planos de previdência privada são relevantes ferramentas para quem está se preparando para a aposentadoria. Os benefícios fiscais concedidos para os dois principais produtos desta classe, o Vida Gerador de Benefício Livre - VGBL e o Plano Gerador de Benefício Livre - PGBL, são as suas principais armas na disputa pelos recursos dos indivíduos que desejam poupar para o futuro. No PGBL se permite a dedução do valor investido no plano do imposto de renda anual até o limite de 12\% (doze por cento) da renda, diferindo o recolhimento do imposto para a data de resgate dos recursos. Em ambos, além de se poder também diferir a tributação sobre os ganhos de capital para o momento do saque, se disponibiliza uma tabela regressiva da alíquota de imposto de renda, que, para investimentos de prazo igual ou superior a dez anos, atinge o valor, por certo baixo para os padrões atuais de voracidade do fisco, de 10\% (dez por cento).

Contudo, não é só para quem está planejando a aposentadoria que os planos de previdência privada são úteis. Em um plano sucessório, o PGBL e o VGBL também podem ser de grande utilidade. Em primeiro lugar, além da acumulação de capital que se realiza por via destes instrumentos, também é possível contratar uma cobertura de morte associada ao plano,

\footnotetext{
${ }^{45}$ CCB, art. 792.
} 
chamada pecúlio, que prevê o pagamento de uma quantia em dinheiro ao(s) beneficiário(s) indicado(s) no caso de falecimento do titular. Aqui se aplicam todas as características e benefícios apontados acima para o seguro de vida.

Em segundo lugar, o(s) beneficiário(s) apontado(s), ainda que não se tenha contratado a cobertura adicional de pecúlio, receberá(ão) da seguradora, quando do falecimento do titular, todo o capital acumulado nos planos. Ora, tal monte não transita por inventário, sendo pago pela seguradora diretamente ao(s) beneficiário(s) em curto espaço de tempo, sem a incidência de custos processuais ou honorários advocatícios. E mais, até o momento, no entendimento do setor de seguros e previdência, tal capital não se considera herança para todos os efeitos de direito, sobre ele, portanto, não incidindo as limitações da legítima dos herdeiros necessários e o Imposto sobre Transmissão Causa Mortis e Doação.

\subsection{Contas conjuntas}

Um dos problemas a se tratar em um plano sucessório é o da liquidez. Os herdeiros, caso não tenham renda ou recursos próprios, muitas vezes, se vêem em uma situação bastante delicada, a de não ter disponibilidade de meios para se manter no curto prazo. Aqui não se trata de direito a patrimônio ou a renda futura, mas exclusivamente de ter recursos livres no momento posterior ao óbito do mantenedor da família.

A utilização das amplamente conhecidas contas conjuntas solidárias, as que podem ser movimentadas em conjunto ou isoladamente (e/ou) pelos titulares, mitiga esta questão. Manter recursos líquidos em instituições financeiras em contas de múltipla titularidade com um ou mais herdeiros fornece flexibilidade ao uso dos recursos, providência essencial para 
algumas estruturas familiares. Na eventualidade da falta do patriarca ou da matriarca da família, o cônjuge sobrevivente, os filhos, ou outro parente qualquer pode ter acesso imediato a uma quantia determinada de dinheiro, que irá possibilitar o pagamento de despesas regulares da família, como alimentação, condomínio, pagamento de empregados domésticos, fatura de cartão de crédito, etc. Também não se pode esquecer das possíveis despesas médicas e dos custos com funeral. Ainda que se disponha de seguros ou planos de saúde, pode ser necessário antecipar pagamentos, para o posterior reembolso.

Contas conjuntas não alteram ou influenciam os direitos dos herdeiros, ou seja, não são propriamente instrumentos de uma arquitetura sucessória patrimonial, mas adicionam a esta importante flexibilidade de curto prazo. O herdeiro que fizer uso do patrimônio do titular da herança disponível em conta conjunta precisará prestar contas no inventário.

Reiteradas decisões judiciais acolhem a tese que "o saldo mantido em conta conjunta é propriedade condominial dos titulares”46, e que há a presunção que cada co-titular é proprietário de parcelas equivalentes dos ativos. Em acórdão em sede de apelação de janeiro de 2006 da Décima Sétima Câmara Cível do Rio de Janeiro se afirma a "propriedade comum dos correntistas sobre o valor dos depósitos.” ${ }^{47}$ Já em julgado recente, de abril de 2009, da Décima Quarta Câmara deste mesmo tribunal, foi decidido em questão onde o de cujus era um dos titulares que, "somente a sua parte, no caso a metade do numerário, deve integrar o monte.»48

\footnotetext{
${ }^{46}$ TJRJ, Acórdão em sede de Agravo de Instrumento, processo 2008.002.39521, Décima Quarta Câmara Cível do Rio de Janeiro. Julgamento 13/04/2009.

${ }^{47}$ TJRJ, Acórdão em sede de Apelação, processo 2005.001.32290, Décima Sétima Câmara Cível do Rio de Janeiro. Julgamento 18/01/2006.

${ }^{48}$ TJRJ, Acórdão em sede de Agravo de Instrumento, processo 2008.002.39521, Décima Quarta Câmara Cível do Rio de Janeiro. Julgamento 13/04/2009.
} 
A princípio este entendimento permitiria ao herdeiro co-titular da conta dispor livremente de sua "parcela presumida" dos recursos. No entanto, de forma alguma os demais herdeiros poderiam ser prejudicados em seus direitos sucessórios em face desta presunção. É necessário apurar a propriedade original dos recursos localizados em conta conjunta e verificar se uma doação do de cujus para o co-titular da conta haveria ocorrido, com a conseqüente necessidade de se colacioná-la no processo de inventário, para que a presunção de co-propriedade pudesse prevalecer.

É por esta complexidade, que se deve utilizar deste veículo com muita cautela. Se a disponibilidade imediata de recursos a alguns herdeiros pode evitar diversos inconvenientes, o mau uso desta facilidade por parte destes pode criar injustiças, desequilíbrios e desavenças no processo de inventário.

\subsection{Holdings patrimoniais}

Uma holding é uma sociedade constituída com o objetivo de deter e reunir bens e direitos, como por exemplo participações em outras sociedades empresárias, imóveis, coleções de arte, etc. A depender das espécies de ativos que compõem o patrimônio familiar, a estruturação de uma holding para concentrar os bens a serem transmitidos aos herdeiros pode facilitar bastante a sucessão planejada e a própria proteção do patrimônio.

O cenário mais propício à utilização deste instrumento se revela quando há significativa concentração do patrimônio do titular da herança em quotas ou ações de sociedades empresarias, onde este participe de alguma forma do controle acionário. Neste caso, após sua morte tais quotas ou ações seriam distribuídas por seus herdeiros, que imediatamente 
passariam a deter o poder de influenciar nas decisões empresariais e operacionais das sociedades. Ocorre que não necessariamente tais herdeiros possuem a vocação empreendedora ou capacidade executiva necessária para tal desafio. Pior, os herdeiros, novos controladores das sociedades, podem não se entender sobre os caminhos a seguir na gestão dos empreendimentos. A constituição de uma holding que concentrará as quotas ou ações das sociedades empresárias pode não só criar conveniente distância entre o controle societário e os atos de gestão, mas também circunscrever o âmbito em que as eventuais disputas societárias serão travadas. Visa-se assim preservar a continuidade do negócio.

Outra situação que pode justificar a criação de uma holding com fins sucessórios é quando a família detenha significativo número de imóveis em seu patrimônio. Em condições normais, ao falecer o titular da herança, cada um dos imóveis precisaria ser inventariado, avaliado, partilhado e formalmente registrado em nome dos herdeiros. O conseqüente imposto de transmissão, muitas vezes majorado por atribuição de excessivo valor de mercado por parte de autoridade governamental competente, e os custos de registro se somariam aos já não irrelevantes custos processuais e advocatícios decorrentes de tamanha manobra burocrática. Caso, no entanto, os imóveis constituíssem o patrimônio de uma holding, a sucessão se restringiria exclusivamente às quotas desta ${ }^{49}$, o que simplificaria enormemente o processo sucessório, além de reduzir significativamente seu custo. E não só isso. Este instrumento pode fornecer ainda sempre importante liquidez aos ativos imobilizados. Debaixo do véu da holding, os imóveis podem ser alienados por seus controladores, eventualmente os próprios herdeiros, a qualquer momento durante o processo de inventário, sem a necessidade de qualquer interferência judicial.

\footnotetext{
${ }^{49}$ A referência exclusiva a quotas (sociedade limitada) e não a ações (sociedade anônima) se deve ao autor acreditar que na hipótese em tela dificilmente não se justificaria a escolha deste modelo societário, pelos custos e complexidades adicionais que acarreta.
} 


\subsection{Escolha do regime de bens}

No sistema do Código Civil de 1916, os descendentes ou, na sua falta, os ascendentes não concorriam com o cônjuge do de cujus. Ou seja, o viúvo(a) somente participaria da partilha dos bens do titular da herança quando não houvesse herdeiros nas outras duas classes preferenciais. Neste contexto, a escolha do regime de bens ganhava enorme relevância quando se tinha o objetivo de planejar a destinação patrimonial de um indivíduo após a sua morte. Ora, em existindo descendentes ou ascendentes, o cônjuge não teria direito a nenhuma parcela do patrimônio acumulado pelo de cujus, caso o regime de bens fosse o da separação. Tampouco herdaria qualquer percentual dos bens particulares de seu esposo(a) no caso do regime de comunhão parcial.

Esta situação mudou por completo no sistema adotado pelo Novo Código Civil. Hoje já não se diferenciam tanto os efeitos patrimoniais de cada regime na ocasião da morte de um dos cônjuges. Se antes se escolhia o regime de separação para que, após a morte, o patrimônio seguisse a linha reta de parentesco, na vigência do atual código, esta opção já não mais existe. O cônjuge agora será sempre herdeiro sob este regime. A mudança afeta da mesma forma o patrimônio particular do cônjuge casado sob o regime de comunhão parcial. Os bens adquiridos antes do casamento ou havidos por doação ou herança, que, antes de 2003, eram destinados integralmente aos descendentes ou ascendentes, e somente na ausência destes, aos cônjuges sobreviventes, hoje serão herdados por este em concorrência com aqueles. 
Assim, resta à escolha do regime de bens papel muito tímido em uma estratégia de sucessão patrimonial. Diz-se tímido, e não inexistente, porque ainda diferentes efeitos relevantes podem ser obtidos. Pensemos na sucessão de um indivíduo que tenha deixado três filhos e cônjuge e que houvesse casado quando já possuísse grande patrimônio ou tenha recebido inúmeros bens por herança. Na hipótese de um regime de bens de comunhão total, o viúvo(a) não herdaria quota alguma destes bens pois, por meação, já seriam seus 50\% (cinqüenta por cento). Já sob o regime de comunhão parcial, ou separação, de bens, este herdaria apenas uma quarta parte do referido patrimônio, sendo certo que os outros três quartos seriam destinados aos descendentes. Ou seja, se os efeitos da escolha do regime de bens hoje já não possibilitam a eliminação total do cônjuge da sucessão de bens, ainda é viável se obter algum grau de influência na situação patrimonial relativa entre cônjuges e descendentes ou ascendentes.

A tabela abaixo resume de forma simplificada as diferenças na condição do cônjuge sobrevivente em relação ao patrimônio adquirido pelo cônjuge falecido em cada regime de bens, quando concorrer com seus descendentes.

Tabela 1

\begin{tabular}{|l|c|c|}
\hline \multirow{2}{*}{ Regime de bens do casamento } & \multicolumn{2}{|c|}{ Tempo e forma de aquisição dos bens } \\
\cline { 2 - 3 } & $\begin{array}{c}\text { Bens adquiridos } \\
\text { antes do casamento } \\
\text { ou por doação ou } \\
\text { herança }\end{array}$ & $\begin{array}{c}\text { Bens adquiridos } \\
\text { onerosamente na } \\
\text { constância do } \\
\text { casamento }\end{array}$ \\
\hline Separação & Herdeiro & Herdeiro \\
\hline Comunhão Total & Meeiro & Meeiro \\
\hline Comunhão Parcial & Herdeiro & Meeiro \\
\hline Participação Final nos Aquestos & Herdeiro & Meeiro \\
\hline
\end{tabular}




\subsection{Cláusulas de incomunicabilidade, impenhorabilidade e inalienabilidade}

Tanto em um testamento, quanto em uma doação em vida, pode-se determinar que os bens transmitidos sejam gravados com uma ou mais destas três cláusulas restritivas: incomunicabilidade, impenhorabilidade e inalienabilidade. A primeira delas, por óbvio, visa exclusivamente à manutenção do bem vinculado na família ${ }^{50}$ do titular da herança. As duas últimas têm o viés claro de proteção ao herdeiro. Segundo Washington de Barros Monteiro, pode ser útil esta vinculação, pois "ampara o beneficiário, pondo-o a salvo de perigosas prodigalidades." ${ }^{51}$

É certo que a inalienabilidade, que torna a coisa indisponível, implica não só na incomunicabilidade, mas também na impenhorabilidade. ${ }^{52}$ "Se assim não fora", assevera Washington de Barros Monteiro, "mui fácil seria burlar o vínculo instituído, bastando ao beneficiário contrair dívidas, deixar de solvê-las no vencimento e aguardar, em seguida, execução do credor sobre os bens clausulados”. ${ }^{53}$

Importante notar, no entanto, que independente das razões para se utilizar tais instrumentos, há uma restrição legal para sua aplicação geral. Estipula o artigo 1.848 do Código Civil que "salvo se houver justa causa, declarada no testamento, não pode o testador estabelecer cláusula de inalienabilidade, impenhorabilidade, e de incomunicabilidade, sobre os

\footnotetext{
${ }^{50}$ Família restritivamente definida, excluindo parentesco derivado do casamento.

${ }^{51}$ MONTEIRO, Washington de Barros. Curso de Direito Civil: Direito das Sucessões. 35 a ed. São Paulo: Editora Saraiva, 2003. pg 177.

${ }^{52}$ CCB, art. 1.911.

${ }^{53}$ MONTEIRO, Washington de Barros. Curso de Direito Civil: Direito das Sucessões. $35^{\mathrm{a}}$ ed. São Paulo: Editora Saraiva, 2003. pg 180.
} 
bens da legítima”. Pode, assim, o herdeiro buscar por sentença a invalidação dos gravames, quando entender que motivo justo não houve.

\subsection{Fideicomisso}

Nas palavras do mestre Caio Mário, o fideicomisso “consiste na instituição de herdeiro ou legatário, com o encargo de transmitir os bens a uma outra pessoa a certo tempo, por morte, ou sob condição preestabelecida”. ${ }^{44}$ A lei civil brasileira permite esta relevante construção sucessória, mas não sem limitar-lhe o potencial de uso. Estipula o Código Civil que "a substituição fideicomissária somente se permite em favor dos não concebidos ao tempo da morte do testador”. ${ }^{55}$ Ou seja, a lógica adotada é a de que se o destinatário final dos bens, o fideicomissário, já estiver concebido ao tempo da abertura da sucessão, deve-se operar uma transmissão direta a este. Tornar-se-á, de acordo com o parágrafo único do artigo 1.952 do Código Civil, nu proprietário dos bens fideicomitidos, convertendo-se em usufruto os direitos do fiduciário.

Outra importante restrição imposta pelo legislador é a vedação à instituição de fideicomissos além do segundo grau. ${ }^{56} \mathrm{O}$ que se pretende com esta medida é evitar o controle prolongado no tempo, ou no limite, perpétuo, do patrimônio. "Nada obsta, todavia, a nomeação plúrima de fideicomissários conjuntos, caso em que vigora entre eles direito de acrescer”. 57

\footnotetext{
${ }^{54}$ PEREIRA, Caio Mário da Silva. Instituições de Direito Civil: Direito das Sucessões. $16^{\mathrm{a}}$ ed. Rio de Janeiro: Editora Forense, 2007. pg. 325.

${ }^{55}$ CCB, art. 1.952.

${ }^{56}$ CCB, art. 1.959.

${ }^{57}$ PEREIRA, Caio Mário da Silva. Instituições de Direito Civil: Direito das Sucessões. $16^{\mathrm{a}}$ ed. Rio de Janeiro: Editora Forense, 2007. pg. 329.
} 
Da própria natureza deste instrumento de transmissão patrimonial é a inalienabilidade dos bens pelo fiduciário. Segundo Caio Mário, sem tal restrição, este não cumpriria a função básica do instituto "conservar para restituir". ${ }^{8}$ No entanto, importante destacar que na eventualidade do fideicomissário vir a falecer antes do fiduciário, ou antes de se realizar condição estabelecida, a propriedade se consolida, sem qualquer restrição dominial, neste. O direito do fideicomissário, portanto, é eventual, ou melhor, possui ele mera expectativa de direito, "dependente de um acontecimento futuro ou do escoamento de um prazo". ${ }^{59}$

\subsection{Trusts}

O trust é um instituto de tradição anglo-saxonica, amplamente difundido e utilizado como ferramenta sucessória nos países que adotam o regime do common law. Baseia-se em uma relação fiduciária onde uma pessoa detém título de propriedade de um patrimônio, trust, sujeito a uma obrigação de mantê-lo ou utilizá-lo em benefício de terceiros. O settlor é a pessoa que intencionalmente cria um trust, transferindo-lhe parte, ou a integralidade de seu patrimônio. O trustee ou fiduciário é a pessoa que detêm o título de propriedade em benefício de outro(s). O beneficiário é a pessoa em benefício de quem o trustee deve manter ou utilizar o patrimônio do trust. ${ }^{60}$

A grande atratividade do trust como instrumento de apóio ao planejamento sucessório é sua flexibilidade. Basicamente, pode-se criar um trust para qualquer objetivo que não seja ilegal ou contrário a ordem pública. As obrigações do trustee podem ser livremente criadas e escolhidas pelo settlor. Os interesses dos beneficiários podem, também, ser livremente

\footnotetext{
58 Ibid, pg. 333.

${ }^{59}$ Ibid, pg. 337.
} 
determinados pelo settlor. Os usos de um trust são tão ilimitados quanto a imaginação dos advogados. ${ }^{61}$

Quando um trust é criado, o seu patrimônio se mantém apartado dos bens e direitos do trustee. Tal construção legal não encontra paralelo nos sistemas jurídicos civilistas. Principal razão esta para não ser possível a criação de um trust em quase nenhum dos países de tradição jurídica romana, incluindo o Brasil.

O trust pode ser criado por ato inter-vivos ou por testamento. Sua utilização se dá, por exemplo, com o intuito de se prover uma gestão profissional do patrimônio do titular da herança, quando há herdeiros menores ou cônjuges sobreviventes que são idosos ou inexperientes em gestão de negócios. Para se evitar a burocracia e o custo dos processos de inventário. Para se reduzir a carga tributária na transferência patrimonial. Ou até para se postergar a transmissão do patrimônio aos herdeiros, situação em que se pode conceder poderes discricionários ao trustee para adequar os direitos sucessórios às alterações familiares ou patrimoniais futuras daqueles. ${ }^{62}$

Há, no entanto, uma significativa limitação ao uso dos trusts nos países que o adotam: a vedação a perpetuidade. Esta restrição possui motivação idêntica a do legislador pátrio quando não permite o fideicomisso de segundo grau, vedar a manutenção prolongada ou perpétua do patrimônio.

Para os indivíduos domiciliados no Brasil, a instituição de um trust em países que adotam o commom law deve ser cercada de precauções. É

\footnotetext{
${ }^{60}$ BOGERT, George. Trusts. $6^{\text {a }}$ ed. St. Paul: Editora West Group, 1987. pg. 1

${ }^{61}$ WRIGHT, L.A. Trusts and the civil law: A comparative study. Western Ontario Law Review. Ontário, Vol. 6, p. 114-127, 1967. pg 114.
} 
indiscutível que se pode obter com este instrumento efeitos sucessórios não previstos ou possíveis por nenhum outro instituto do direito civil. Efeitos estes que podem ser insubstituíveis na busca por se fazer prevalecer a vontade do de cujus. Contudo, há de se respeitar os limites da legislação pátria. Os direitos dos herdeiros necessários, as obrigações tributárias, e as regras para transferência de ativos ao exterior são alguns dos principais.

\section{A IMPORTÂNCIA DA SELEÇÃO DA CARTEIRA DE ATIVOS}

Planejar a sucessão patrimonial passa também por algo que pouca relação tem com os instrumentos jurídicos e financeiros listados acima: a escolha dos tipos de ativos que serão transmitidos aos herdeiros. Ao longo de suas vidas, os indivíduos acumulam seus patrimônios em diversos tipos de ativos: imóveis, fundos de investimentos, ações de sociedade anônimas listadas em bolsa de valores, títulos públicos, moedas estrangeiras, poupança, planos de previdência, etc. A escolha destes ativos é influenciada por inúmeras, ou provavelmente, infinitas, motivações. Tem lugar aqui a preferência pessoal, o apetite ao risco, o grau de instrução financeira, a herança cultural, as oportunidades de aquisição que se teve acesso, a atividade profissional desenvolvida, a região de domicílio, etc. No entanto, as inúmeras estratégias patrimoniais decorrentes quase sempre visam a acumulação e a proteção patrimonial. No momento da sucessão, no entanto, as prioridades podem ser outras, como tivemos a oportunidade de debater ao longo deste trabalho. Logo, a composição da carteira de ativos a transmitir aos herdeiros não necessariamente deve ser aquela que se carrega ao longo de toda uma vida.

\footnotetext{
${ }^{62}$ AVERILL, Lawrence H.. Wills, Trusts, \& Future Interests. $3^{\mathrm{a}}$ ed. St. Paul: Editora West Group, 2005. pg. 417.
} 
Podemos dividir os ativos em duas grandes classes: a dos ativos ilíquidos e a dos ativos líquidos. Nesta se incluem os fundos de investimento, as ações comercializadas em bolsa e os títulos públicos. Naquela, os bens imóveis, as participações societárias em sociedades empresariais familiares, e os direitos creditícios. A mais relevante distinção entre as duas classes no que tange a sucessão patrimonial é a constituição dos nem sempre desejáveis condomínios. Os ativos líquidos, por sua própria natureza, são divisíveis e facilmente transformáveis em moeda corrente, assim garantem independência de ação para cada herdeiro ao receber sua quota hereditária. Os ilíquidos, por sua vez, acarretam uma relação de co-propriedade quando são transmitidos a mais de um herdeiro.

Aqui já se tem um importante direcionador para um plano sucessório. Caso a sucessão tenha como cenário um elevado número de herdeiros, complexas relações familiares, ou um ambiente beligerante, deve se evitar a alocação patrimonial em ativos ilíquidos. E se isto não for por todo viável, urge influenciar, por via testamentária, por exemplo, a distribuição dos bens, individualizando sempre que possível os ativos destinados a cada herdeiro, evitando ao máximo o condomínio. Por outro lado, em um cenário distinto, onde poucos são os herdeiros, e a preocupação se concentre no uso que será dado ao patrimônio após a sucessão, pode ser mais aconselhável mantê-lo sob a forma de ativos ilíquidos. Pense-se, por exemplo, a hipótese de descendentes ainda jovens e com ímpeto aventureiro próprio da idade. Neste caso, uma carteira concentrada em ativos ilíquidos proverá maior chance à manutenção patrimonial.

A seleção da carteira de ativos para a sucessão, no entanto, não diz respeito apenas a composição desta. Fator igualmente importante é a escolha dos herdeiros que receberão cada ativo ou bem que a compõe. Pode o testador, respeitando o valor global da legítima de cada herdeiro, escolher 
os bens e ativos que cada um de seus sucessores irá receber. Alias não só via testamento, por doação em vida, como já visto, também se pode exercer esta faculdade. Adicionar este último pilar à arquitetura sucessória é garantir sua adequação às características, preferências e contextos de vida individuais de cada herdeiro.

\section{CONCLUSÃo}

Um plano sucessório patrimonial eficaz depende de um profundo conhecimento dos desejos, preocupações e preferências do titular do patrimônio. Mas isto é só o início. Necessita também se adaptar à estrutura familiar deste e às características pessoais e às necessidades mais especiais de cada um de seus herdeiros. Precisa ter a necessária flexibilidade para se adaptar às imprevisíveis, porém certas, surpresas da vida. Deve minimizar os conflitos familiares, além de facilitar a transição da titularidade do patrimônio. E por fim, tem que respeitar as limitações legais e as previsões tributárias.

Para se lograr todos estes objetivos, no entanto, tem-se a disposição um completo arsenal de instrumentos jurídicos e financeiros. Utilizando-os, em conjunto ou isoladamente, pode-se obter os mais diversos e significativos efeitos no patrimônio, nas relações familiares e afetivas, nos sonhos e na qualidade de vida dos futuros herdeiros.

Nunca é cedo ou tarde demais para se construir uma arquitetura sucessória patrimonial adequada. Qualquer iniciativa coerentemente pensada e implementada, por mais tarde no ciclo de vida do indivíduo que se coloque, irá aproximar os efeitos patrimoniais de sua morte aos seus desejos. Por outro lado, um plano elaborado hoje, que somente venha a trazer efeitos concretos décadas à frente, pode ser periodicamente adaptado para refletir os diferentes cenários de vida pelos quais os indivíduos inevitavelmente transitam. 


\section{REFERÊNCIAS BIBLIOGRÁFICAS:}

ARAUJO, Nadia. Direito Internacional Provado: Teoria e Prática Brasileira. $4^{\mathrm{a}}$ ed. Rio de Janeiro: Editora Renovar, 2008. 620 p.

AVERILL, Lawrence H.. Wills, Trusts, \& Future Interests. $3^{\mathrm{a}}$ ed. St. Paul: Editora West Group, 2005. 784 p.

BEVILAQUA, Clovis. Direito das Sucessões. $2^{\text {a }}$ ed. Rio de Janeiro: Editora Freitas Bastos, 1932. 440 p.

BOGERT, George. Trusts. 6ª ed. St. Paul: Editora West Group, 1987. 793 p.

GAMA, Guilherme Calmon Nogueira. Direito Civil: Sucessões. $2^{\mathrm{a}}$ ed. São Paulo: Editora Atlas, 2007. 323 p.

GONÇALVES, Carlos Roberto. Direito Civil Brasileiro: Direito de Família. $1^{\text {a }}$ ed. São Paulo: Editora Saraiva, 2005. 340 p.

MAXIMILIANO, Carlos. Direito das Sucessões. 2a ed.. Rio de Janeiro: Editora Freitas Bastos, 1942. (3 vol.)

MONTEIRO, Washington de Barros. Curso de Direito Civil: Direito das Sucessões. 35ª ed. São Paulo: Editora Saraiva, 2003. 340 p.

Id., Curso de Direito Civil: Direito das Coisas. $37^{\mathrm{a}}$ ed. São Paulo: Editora Saraiva, 2003. 469 p.

NONATO, Orosimbo. Estudos sobre sucessão testamentária. $1^{\mathrm{a}}$ ed. Rio de Janeiro: Editora Forense, 1957. (3 vol.)

PEREIRA, Caio Mário da Silva. Instituições de Direito Civil: Contratos. $12^{\mathrm{a}}$ ed. Rio de Janeiro: Editora Forense, 2006. 604 p.

PEREIRA, Caio Mário da Silva. Instituições de Direito Civil: Direito das Sucessões. 16 ${ }^{\mathrm{a}}$ ed. Rio de Janeiro: Editora Forense, 2007. 501 p.

VENOSA, Sílvio de Salvo. Direito Civil: Direito das Sucessões. $9^{\mathrm{a}}$ ed. São Paulo: Editora Atlas, 2009. 420 p.

WRIGHT, L.A. Trusts and the civil law: A comparative study. Western Ontario Law Review. Ontário, Vol. 6, p. 114-127, 1967 